\title{
VIDA URBANA E MODERNIDADE NAS OBRAS DE CARL SCHORSKE, RICHARD SENNET E MARSHALL BERMAN.
}

\author{
Rafael Augustus Sêga*
}

\section{RESUMO:}

O presente artigo pretende fazer uma breve exposição dos livros de Carl E. Schorske, "Viena fin-desiècle, política e cultura."; de Richard Sennet, "O declínio do homem público, as tiranias da intimidade."; e de Marshall Berman, "Tudo que é sólido desmancha no ar, a aventura da modernidade." Procuramos tecer uma rede capaz de captar as manifestações sobre vida urbana e modernidade nas obras de autores com formações acadêmicas distintas e como eles abordam tais questões. Para tanto, assuntos distintos como literatura, história de processos urbanos, psicologia social, arquitetura e pensamento político, etc. foram utilizados.

Em sua obra "Viena fin-de-siècle, política e cultura", o historiador Carl E. Schorske estuda a cidade de Viena ao final do século XIX, metodologicamente destacamos as inúmeras fontes utilizadas pelo autor: literatura, fotografias, pensamento social, música, psicanálise, pinturas. Com tais elementos ele tece uma rede que captou com maestria a realidade da cidade e do período aludidos.

Schorske parte de uma preocupação com a cultura a-histórica novescentista onde o moderno "serve-nos para diferenciar nossas vidas e nossos tempos de tudo o que o procedeu, de toda a história enquanto tal. A arquitetura moderna, a música moderna, a filosofia moderna, a ciência moderna - todas se definem não a partir do passado, e na verdade nem contra o passado, mas em independência do passado. A mentalidade moderna tornou-se cada vez mais indiferentes à história porque esta, concebida como uma tradição nutriz contínua, revelou-se inútil para ela." (Página 13)

A idéia de um processo histórico calcado na vida cultural permite, metodologicamente, ao historiador aproximar-se de fontes onde o auxílio de outras disciplinas é fundamental. Desse modo, se o estudioso da história ignorar análises de especialistas da música, teatro, literatura, psicologia, etc., corre o sério risco de interpretar mal o significado histórico de seu material. O historiador deve situar e interpretar tal material temporalmente: um corte vertical, ou diacrônico, onde ele estabelece a relação desse material com expressões anteriores no mesmo ramo da atividade cultural; o outro, horizontal, ou sincrônico, onde o historiador avalia a relação do conteúdo do objeto intelectual com outros fenômenos que surgem ao mesmo tempo, simultaneamente, em outros ramos da cultura.

O autor trabalha no campo da "história das idéias", analisando separadamente os diversos ramos da atividade cultural, mas sem perder as relações sincrônicas. O fio condutor entre eles é a interação entre política e cultura.

É interessante ver como é trabalhada a cidade como uma entidade cultural, com uma coesão orgânica, onde convivem tradicionalismo e modernismo, provincialismo e cosmopolitismo.

Em Viena, no início do século XX, ocorreu um problema com a arquitetura e o urbanismo da cidade. Foi construído um boulevard, o Ringstrasse, onde os mais variados estilos arquitetônicos fluíram, cujo sistema político liberal se expressou através 
da forma urbana e do estilo arquitetônico. A maneira de construir era toda carregada de ornamentos, isso suscitou a reação do arquiteto Adolph Loos, um moralista que se mostrou contra ao que lhe parecia uma forma aberrante de construção cuja forma seria expressar no exterior o que ocorria no interior das edificações. Loss fez a apologia das cidades com paredes brancas, nas quais os limites entre o interior e o exterior estivessem bem determinados. No entanto, dois outros arquitetos, Otto Wagner e Camillo Sitte, representaram um crítica à política liberal com o surgimento de tendências discordantes dela, a comunitarista e a funcionalista.

O sociólogo norte-americano Richard Sennet em seu livro "O declínio do homem público, as tiranias da intimidade", como o próprio título indica, trata da decadência da vida pública, do narcisismo e da apatia política. Sua fala se enquadra mais no campo da sociologia, nas chamadas "micromutações", sem o peso de um instrumental teórico ortodoxo, muitas vezes inútil, que várias vezes deixa passar inadvertidos fenômenos "sem importância" ante as verdadeiras instâncias de mudança. Sennet dirige seu trabalho justamente a esses fenômenos supostamente sem importância.

A ótica intimista é impulsionada na medida em que o domínio público é esvaziado, desprovido de sentido. É o que acontece com o espaço público (urbano), onde arquitetos e urbanistas são forçados a levar em conta em seus projetos as idéias a respeito da vida pública em seu atual estado de esvaziamento. $\mathrm{O}$ autor trabalha com a hipótese de que esses sinais gritantes de uma vida pessoal desmedida e de uma vida pública esvaziada ficaram por muito tempo latentes e são resultados da queda do Ancien Régime e da formação de uma nova cultura urbana, secular e capitalista. Assim, o ambiente "público" passa a significar uma vida que se passa fora do âmbito familiar e dos amigos íntimos, já que na região pública os grupos heterogêneos entram em contato e o centro dessa vivência é a cidade.

Sennet esquematiza na obra três forças de transformação em atividade no século XIX que alteraram a vida pública: as transformações econômicas operadas pelo capitalismo industrial, as transformações políticas atestadas em termos de credibilidade públicas operadas por uma nova secularização e as transformações culturais que transformaram o próprio comportamento público em razão da sobrevivência de uma faceta da ideologia pública do Ancien Régime.

Nos estudos urbanísticos, as palavras "urbano" e "urbanizar" não são bem claras. Usa-se "urbano" para referirmos um lugar no mapa e à sua vida, já "urbanizar" passa a significar a expansão desse estilo de vida para outros lugares além da cidade física. No entanto, este uso é inadequado quando nos reportamos à sociedade burguesa européia do século XIX, uma vez que quem construiu a cidade foi um sistema administrativo, financeiro e jurídico, e não o contrário. A urbanização no século XIX consistia em alguma coisa a mais do que a difusão de hábitos urbanos, significava uma difusão mais ampla de forças ditas "modernas", ou "antitradicionais".

O foco de interesse de Richard Sennet se volta para Paris, especialmente. Walter Benjamin escreveu que essa cidade era tanto "a capital do século XIX" como única. Foi a relação entre cultura e política que fez de Paris a principal cidade do século XIX para Benjamin. Lá os conflitos ideológicos eram levados aos extremos e as sublevações 
revolucionárias, temidas em outras cidades, desempenharam papel importante na experiência ou na memória coletiva dos parisienses.

Há um século, os planejadores urbanos comprometeram-se em construir e preservar o território da comunidade na cidade como um ojetivo social. Camillo Sitte foi o primeiro urbanista que se revoltou contra a escala monumental do projeto do Barão Haussmann pra Paris. Os planejadores atuais desistiram de uma concepção global de cidade, porque reconhecem as limitações dessa concepção e sua influência política. A geração de Sitte concebia a comunidade dentro da cidade e o urbanista de hoje concebe a comunidade contra a cidade.

As verdadeiras idéias sobre o projeto do Barão de Haussmann estavam baseadas na homogeneização. Os novos distritos da cidade deveriam ser de uma só classe e, no antigo centro da cidade ricos e pobres deveriam ser isolados uns dos outros. Era o início do desenvolvimento urbano de "função única". Cada espaço da cidade deveria desenvolver uma atividade particular, e a própria cidade ser atomizada. A atomização da cidade colocou um fim prático num componente essencial do espaço público: a superposição de funções dentro de um mesmo território, o que resultou em complexidades de experiências naquele determinado espaço. O esforço de Haussmann visava entrelaçar necessidades de trabalho, criação dos fillhos, sociabilidade adulta e encontros impessoais dentro e em volta de uma mesma casa.

"Cidade" e "civilidade" têm raiz etmológica comum. "Civilidade" trata os outros como estranhos e forja um nexo social sobre essa distância social. A cidade é o estabelecimento humano no qual os estranhos devem provavelmente se encontrar. A geografia pública de uma cidade é a institucionalização da civilidade. Em um mundo sem rituais religiosos e nem crenças transcendentais profundas, as máscaras sociais são criadas por seus usuários, por intermédio de um desejo de viver com os outros mais do que a pela compulsão de estar perto dos outros. Quanto mais esse comportamento toma corpo, mais se torna viva a mentalidade sobre a cidade e o amor por ela.

O livro "Tudo que é sólido desmancha no ar, a aventura da modernidade" do filósofo norte-americano Marshall Berman pode ser considerado um clássico na área das ciências humanas. Berman trabalha em seu texto duas noções muito caras para quem se dispõe a estudar a sociedade contemporânea: modernidade e revolução.

A argumentação básica do livro é a seguinte: "Existe um tipo de experiência vital - experiência de tempo e espaço, de si mesmo e dos outros, das possibilidades e perigos da vida - que é compartilhada por homens e mulheres em todo o mundo hoje. Designarei esse conjunto de experiência como 'modernidade'. Ser moderno é encontrarse em um ambiente que promete aventura, poder, alegria, crescimento, autotransformação e transformação das coisas ao redor - mas ao mesmo tempo ameaça destruir tudo o que temos, tudo o que sabemos, tudo o que somos. A experiência ambiental da modernidade anula todas as fronteiras geográficas e raciais, de classe e nacionalidade, de religião e ideologia: nesse sentido, pode-se dizer que a modernidade une a raça humana. Porém, é uma unidade paradoxal, uma unidade de desunidade: ela nos despeja a todos num turbilhão de permanente desintegração e mudança, de luta e contradição, de ambigüidade e angústia. Ser moderno é fazer parte do universo no qual, como disse Marx, 'tudo que é sólido desmancha no ar'". (Página 15) 
Aos processos sociais de mudança, entre eles as formas de expansão urbana impulsionados pelos mercados capitalistas, dá-se o nome de "modernização", e à visào cultural engendrada pelos atores sociais, "modernismo", entre esses dois termos encontra-se a idéia-chave, "modernidade", a experiência histórica, que é sentida tanto em termos de transformação no mundo físico como na personalidade das pessoas, que estão em permanente estado de tensão frente a essas gigantescas, por não dizer fantasmagóricas, transformações que passam a ocorrer.

A frase-título do livro foi extraída do "Manifesto Comunista" de Marx e Engels e significa o arrasamento do confinamento ancestral e toda restrição feudal, uma "limpeza" nos entulhos culturais do mundo.

Esse processo significa uma espetacular emancipação das possibilidades e da sensibilidade da personalidade individual, que se liberta da impossibilidade do status e da hierarquia de papéis rígida das sociedades pré-capitalistas, entretanto, esse avanço do desenvolvimento econômico capitalista gera uma sociedade alienada e fragmentada, dilacerada pela exploração econômica e pela indiferença social, capaz de destruir valores culturais e políticos que ela mesmo criou. No plano psicológico essas condições geram profunda insegurança e desorientação, desespero e frustração, contrastando com um senso de regozijo e expansão, novas capacidades e sentimentos liberados ao mesmo tempo. Para Berman: "esta atmosfera de agitação e turbulência, vertigem e embriaguez psíquica, expansão das possibilidades da experiência e destruição das fronteiras morais e dos laços pessoais, auto-expansão e autoperturbação, fantasmas na rua e na alma" (Página 18) é a atmosfera em que nasce a sensibilidade moderna.

Assim como C. E. Schorske, metodologicamente, Berman faz uso da literatura como fontes, Goethe com "Fausto" dá a visão da dualidade da tragédia moderna: "abrir as comportas do eu, à custa de represar o oceano." Marx no "Manifesto" e Baudelaire em "Fleurs du Mal" são vistos como precursores da descoberta da modernidade. Descoberta na qual em uma sociedade onde a modernização foi feita de cima para baixo numa sociedade atrasada como a russa do século XIX, prolonga-se uma tradição literária que ainda conserva a memória de como era viver em um mundo pré-moderno. Isto é atestado na obra de Pushkin, Gogol, Dostoievski e Mandelstam. A cidade é lida também como expressão dessa modernidade, ambientes espaciais e sociais: grandes empreendimentos de construção civil, o Palácio de Cristal de Joseph Paxton, os bulevares parisienses de Haussmann, os projetos de Petersburgo ou as rodovias de Robert Moses através de Nova Iorque.

Por fim, a intenção do presente artigo foi tentar tecer uma rede que pudesse captar as manifestações sobre vida urbana e modernidade nas obras dos autores supracitados, uma vez que suas formações acadêmicas são bem distintas. Como toda seleção, ela foi arbitrária, mas esperamos ter conseguido conciliar assuntos diversos como literatura, história de processos urbanos, psicologia social, arquitetura, pensamento político, etc. em nosso intuito.

\section{REFERÊNCIAS BIBLIOGRÁFICAS:}


BERMAN, Marshall. Tudo que é sólido desmancha no ar, a aventura da modernidade. São Paulo: Companhia das Letras, 1986.

SCHORSKE, Carl E. Viena fin-de-siècle, política e cultura. São Paulo: Companhia das Letras/Editora da UNICAMP, 1988.

SENNET, Richard. O declínio do homem público, as tiranias da intimidade. São Paulo: Companhia das Letras, 1988. 